\title{
Looking for hidden signs of consciousness
}

Can brain-injured patients who show no response to their surroundings ever be considered conscious? This question became a hot topic last year after researchers who scanned the brain of a woman diagnosed as being in a vegetative state found that she could perform certain mental tasks on request.

The same team has now validated its scanning method on healthy volunteers, and believe that it can be used as a general method for measuring consciousness in unresponsive patients. The researchers are also using real-time brain scanning to try to ask questions of patients who pass the test.

Given that there is no consensus about what it even means to be conscious, it is perhaps not surprising that it is difficult to find an objective way of detecting any trace of it in patients in a vegetative state.

A test is needed, nevertheless, says Steven Laureys, a team member at the University of Liège in Belgium. Some signs of consciousness have been found in up to $40 \%$ of patients in an apparent vegetative state when they are studied more closely, suggesting that such patients are often misdiagnosed.

In the high-profile case reported in Science last year, the team, led by Adrian Owen of the MRC Cognition and Brain Sciences Unit in Cambridge, UK, used functional magnetic resonance imaging (fMRI) to show that a woman left in a vegetative state after a car accident could respond to requests to imagine playing tennis or navigate around her house (A. Owen et al. Science 313, 1402; 2006).

The team has now tested this technique on 24 healthy volunteers, who were similarly instructed to imagine either walking around

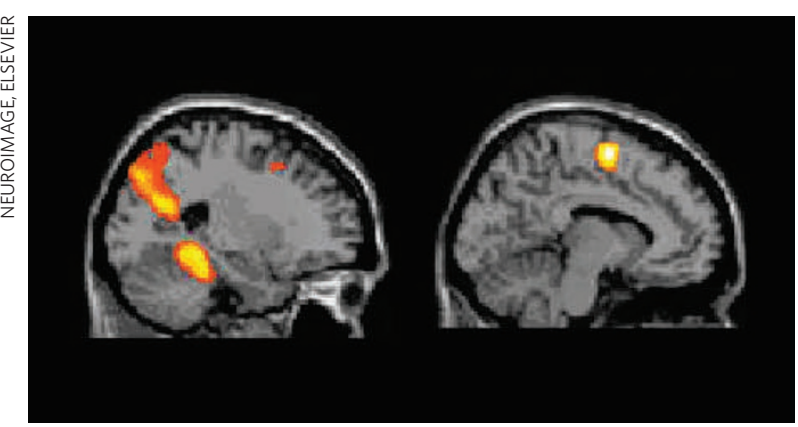

Imagining spatial navigation (left) and playing tennis. their house or playing tennis. The tasks activate separate networks in the brain, and the scans proved able to tell correctly which task was being performed (M. Boly et al. NeuroImage doi:10.1016/j.neuroimage.2007.02.047; 2007).

The researchers say that showing that the method works reliably in healthy brains proves its robustness. "Our challenge is to find markers that tell us 'this is a hopeless case' or 'this is a case where we should increase our therapeutic efforts,"' says Laureys.

Laureys has since used the technique in five vegetative-state patients in Liège, but none has shown brain activity compatible with consciousness. Owen has tried with three patients in Cambridge — and found one man capable of responding. His team went on to try two-way communication with this patient and with the girl originally described in Science, using real-time brain scanning. The patients were instructed that to answer 'yes' to a question they should imagine playing tennis (or football — the team knew the man was an avid Liverpool fan), and for 'no' to imagine walking around their house.

This is considerably more complex than the original task and neither patient has responded, but Owen is confident that some patients will be capable of doing so. "It's probably only a matter of time," he says. Because doing fMRI scanning requires transporting patients to a hospital that has a scanner, Owen is also investigating the idea of fitting patients with electroencephalogram (EEG) caps that would measure their brainwaves and use this activity to move a cursor around a computer screen. Patients who passed the initial fMRI test could then be extensively followed up using EEG.

Not everyone is convinced that the test is ready for diagnostic use. Even if patients do not respond, cautions Nicholas Schiff, a neurologist at Weill Cornell Medical College in New York, it is still not possible to tell exactly what this means. Does the patient understand the question? Do they not want to respond? "This is not ready for primetime," says Schiff. Kerri Smith

\section{ON THE RECORD \\ c(You're a big daft cock.)}

The entire response of Martin Durkin, director of a recent British television documentary The Great Global Warming Swindle, to a reasoned e-mail from Imperial College scientist Armand Leroi questioning the programme's accuracy.

\section{SCORECARD}

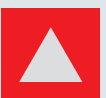

Being fat

Obese men are less prone to suicide,

according to a 20-year survey, although the study's authors do not recommend overeating as a healthy route to happiness.

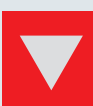

Living on the Moon

NASA has set up a working group to investigate whether toxic dust could make 'lunar hay fever' an occupational hazard of living on a Moon base.

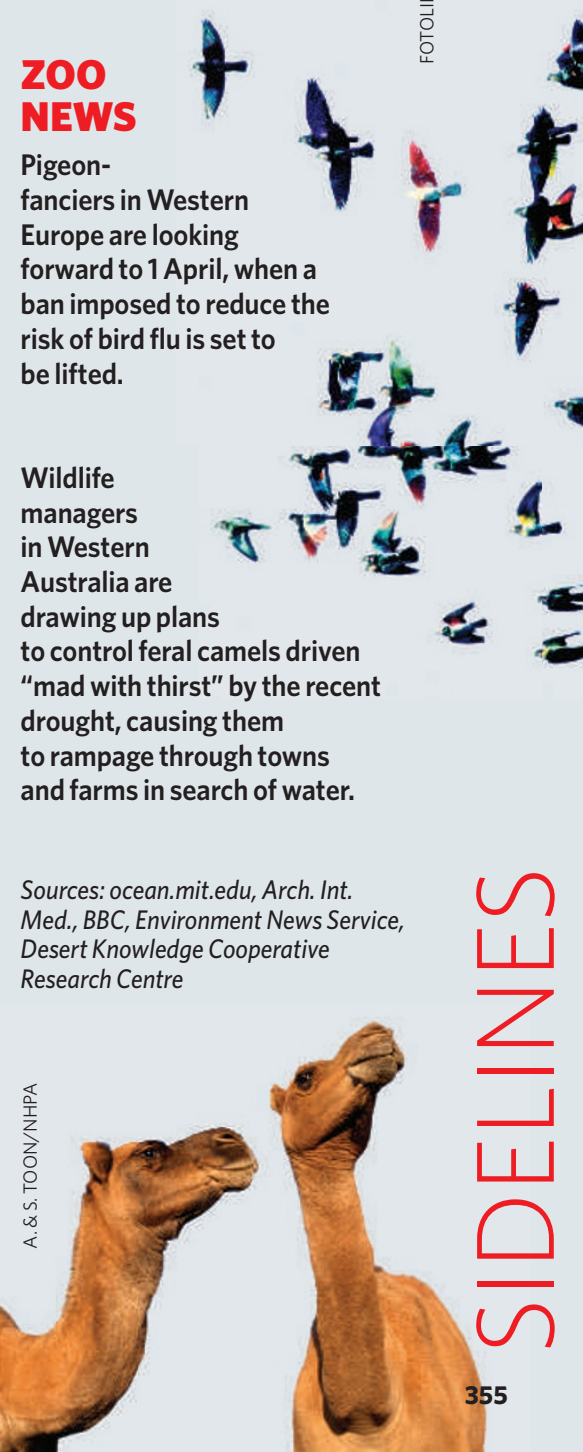

